\title{
Lebensbericht über den Weg von Weimar nach Westminster
}

\section{Rost, Peter: Weimar to Westminster. An Autobiography, Dynasty Press, London 2010, 330 Seiten, $€ 16,99$.}

Als Harold Wilson nach seinem überraschenden Rücktritt am Ende seiner zweiten Amtszeit als Premierminister 1976 in einem Fernsehinterview gefragt wurde, welcher Oppositionsabgeordneter ihm die meisten Schwierigkeiten bereitet habe - die Gesprächspartner dachten dabei vor allem an die wöchentliche „Prime Minister's Question Time“ im Unterhaus -, nannte der scheidende Labourchef die Namen Norman Tebbit, Nigel Lawson und Peter Rost. Die beiden Erstgenannten wurden später prominente Kabinettminister unter Margaret Thatcher, Peter Rost dagegen blieb bis zu seinem Ausscheiden aus dem Unterhaus 1992 nach 22-jähriger Parlamentszugehörigkeit ein Backbencher. Ministerielle Ämter blieben ihm versagt. Seine Jahre als Parlamentarier, der Alltag in Westminster und seine Arbeit im Wahlkreis bilden Schwerpunkte der Autobiographie von Rost, der heute überwiegend in Südfrankreich lebt. Seinen Lebensbericht „Weimar to Westminster" versteht der Autor vor allem als Zeichen der dankbaren Wertschätzung der durch Westminster verkörperten liberalen demokratischen Ordnung Großbritanniens. Zugleich gibt er ein anschauliches Panorama der britischen Regierungs- und Parlamentsmaschinerie in den siebziger und achtziger Jahren des vergangenen Jahrhunderts. Der Autor beginnt mit „Weimar“, seinen deutschen Wurzeln: Der siebenjährige, im Berlin der Weimarer Republik geborene Otto Ludwig Peter Rosenstiel kam 1937 als Flüchtling aus Deutschland nach England. Seinem jüdischer Vater, Frederick Rosenstiel, Journalist bei der Frankfurter Zeitung, war klar geworden, dass es für ihn und seine nichtjüdische Ehefrau keine Zukunft mehr in Nazi-Deutschland geben würde. Bereits im Jahr darauf wird aus dem jungen deutschen Flüchtling der Schüler Peter Rost. Es folgen Evakuierung, häufiger Wohn- und Schulwechsel. Schon früh findet Rost seine politische Heimat bei den Konservativen, es sind die Boomjahre der „Young Conservatives“. Während seines Studiums verstärkt er sein politisches Engagement und wird Mitglied der „University Conservative Party“. Seinen beruflichen Einstieg findet der Universitätsabsolvent im Journalismus. Nicht ohne die hilfreichen Beziehungen des Vaters, der sich inzwischen in New York als Wall Street-Berichterstatter etabliert hat, wird Rost Redaktionsmitglied beim Wirtschaftsblatt „Investors' Chronicle“. 1958 wechselt er als Börsenmakler an den Stock Exchange. Parallel dazu engagiert Rost sich verstärkt parteipolitisch, und es gelingt ihm schließlich, beim „Central Office“, der konservativen Parteizentrale, auf die Kandidatenliste für Wahlen zum Unterhaus zu kommen.

Im zweiten Anlauf gewinnt Rost 1970 einen bisher von Labour gehaltenen Unterhaussitz. Der überraschende Wahlsieg der Konservativen beendet die erste, sechsjährige Amtszeit des Labour-Führers Harold Wilson, und Edward Heath, Parteichef der Konservativen seit 1965, wird Premierminister. 1971 wird der neugewählte Abgeordnete und leidenschaftliche ProEuropäer Zeuge des knappen Votums zugunsten des EG-Beitritts, im persönlichen Rückblick das bedeutendste Ereignis in seiner Zeit als Parlamentarier. Im Gefolge des Streiks der Bergarbeiter wird die Regierung Heath 1974 abgewählt, und bereits im Jahr darauf wird Heath als Parteiführer gestürzt. Beim Nachfolgekampf stimmt Rost für Margaret Thatcher.

Über viele Jahre war Rost, ein früher Anhänger erneuerbarer Energien, Mitglied des Select Committee on Energy. 1990 ist er ernsthafter Kandidat für den Ausschussvorsitz, scheitert aber am Einfluss der Government Whips und damit letztlich der Exekutive und der Partei- 
organisation, die auch bei den Ausschussbesetzungen, eigentlich eine ureigene Angelegenheit des Parlaments, das Sagen haben.

Rost verstand sich immer als „caring Member“ und berichtet instruktiv über seine Wahlkreisarbeit und den Parlamentsalltag. Über viele Jahre ist er aktives Mitglied der „BritishGerman Parliamentary Group“, die Förderung der Beziehungen zu seinem Herkunftsland ist ihm ein wichtiges Anliegen.

Am Ende seiner parlamentarischen Laufbahn macht sich resignative Erkenntnis breit: Wahrscheinlich - so Rost - stand ihm eine sehr deutsche Eigenschaft im Wege; zu ernst schien er das Leben genommen zu haben, und zu strikt trennte er seine politisch-parlamentarische Arbeit von den sozialen und gesellschaftlichen Aktivitäten. Viel Zeit verbrachte er in der Parlamentsbibliothek, jedenfalls mehr als in den Bars des Unterhauses. Auch lernte er nie die Regeln des „Old Boys‘ network“.

Joachim Rott

\section{Bilder und Befunde zum Bundestag als Bauherr}

Buslei-Wuppermann, Agatha und Andreas Zeising (Hrsg.): Das Bundeshaus von Hans Schwippert in Bonn. Architektonische Moderne und demokratischer Geist. Mit einem Vorwort von Wolfgang Pehnt, Grupello Verlag, Düsseldorf 2009, 175 Seiten, € 29,90.

Galetti, Nino: Der Bundestag als Bauherr in Berlin. Ideen, Konzepte, Entscheidungen zur politischen Architektur (1991-1998) (Beiträge zur Geschichte des Parlamentarismus und der politischen Parteien, Band 152), Droste Verlag, Düsseldorf 2008, 411 Seiten, € 74,-.

Die beiden genannten Bücher zu rezensieren, fällt leicht und macht Freude, denn in dem einen Fall handelt es sich um eine reich bebilderte von Kunsthistorikern herausgegebene Studie mit gut lesbaren Texten, die den Leser in die Gründerjahre der „Bonner Republik“ entführt. Im anderen Fall ist es eine vom Präsidenten des Deutschen Bundestages ausgezeichnete politikwissenschaftliche Dissertation, die - ebenfalls mit Abbildungen versehen und ohne sich in Details zu verlieren - quellen- und anmerkungsgesättigt die Entscheidungsprozesse im Deutschen Bundestag nachzeichnet, als dieser begann, die „Berliner Republik“ architektonisch zu gestalten. Dazwischen liegen mehr als 40 Jahre und ein verändertes Demokratieverständnis. Standen die ersten Regierungsbauten in Bonn noch ganz im Zeichen des bescheidenen Provisoriums unter alliierter Besatzungsherrschaft, so sah sich der Bundestag gezwungen, im Schatten des Berliner Reichstagsgebäudes großstädtisch zu planen und eine selbstbewusste - weil inzwischen bewährte - parlamentarische Demokratie zu repräsentieren. Anhand der anzuzeigenden Werke kann das Diktum der Bundestagspräsidentin Rita Süssmuth überprüft werden, die anlässlich der Einweihung des Plenarsaalneubaus von Günter Behnisch in Bonn 1992 formulierte, dass Parlamentsgebäude „selbst ein bestimmtes Demokratieverständnis zum Ausdruck bringen“.

Wie sehr sich das Selbstverständnis verändert hat, zeigt der alltägliche Sprachgebrauch. Während in Bonn der Parlamentsbau sogar von Hans Schwippert als „Haus der Bundesregierung“, später dann aber als „Bundeshaus“ bezeichnet wurde, wird in Berlin vom „Reichstagsgebäude“ (nur verkürzt, aber falsch von „Reichstag“) gesprochen; das gesamte Areal - 